\title{
Coexistence of diffuse panbronchiolitis and sarcoidosis revealed during splenectomy: a case report
}

Tomohiro Akaba ${ }^{1}$, Kiyoshi Takeyama ${ }^{1 *}$, Mitsuko Kondo ${ }^{1}$, Fumi Kobayashi', Asako Okabayashi ${ }^{1}$, Tatsuo Sawada ${ }^{2}$ and Etsuko Tagaya ${ }^{1}$

\begin{abstract}
Background: Sarcoidosis is a systemic granulomatous disease caused by CD4+ cell-dominant inflammation. Meanwhile, diffuse panbronchiolitis is a chronic inflammatory respiratory disease predominantly caused by CD8+ lymphocytes and neutrophils. Herein, we report a rare case of sarcoidosis in which the clinical presentation had become evident as diffuse panbronchiolitis after splenectomy for sarcoidosis.
\end{abstract}

Case presentation: A 23-year-old Japanese woman was referred to our hospital due to splenomegaly of unknown etiology. Upon admission, chest computed tomography scan revealed centrilobular and randomly distributed small nodules in both lungs. Bronchoalveolar lavage revealed a high proportion of lymphocytes and a decreased CD4/CD8 ratio. However, the biopsy specimens obtained from both the liver and lungs revealed noncaseating epithelioid granulomas, which confirmed the diagnosis of sarcoidosis. The patient underwent splenectomy due to progressive cytopenia and high risk of splenic rupture. After the surgery, the condition of the patient was consistently good for 3 months. Then, she gradually developed productive cough and dyspnea. Both sinus and chest computed tomography scan revealed chronic paranasal sinusitis and deterioration of centrilobular nodules in both lung fields, respectively. The second bronchoalveolar lavage revealed a high proportion of neutrophils, and the bronchoalveolar lavage fluid tested positive for Hemophilus influenzae. The titer of cold agglutinin was elevated, thereby confirming the diagnosis of diffuse panbronchiolitis. On the basis of the clinical and radiological findings, the condition of the patient improved with low-dose macrolide therapy for 3 months.

Conclusions: The coexistence of sarcoidosis and diffuse panbronchiolitis has not been previously reported, and the hidden profiles of diffuse panbronchiolitis may have been revealed by splenectomy.

Keywords: Sarcoidosis, Diffuse panbronchiolitis, Splenectomy, CD4/CD8 ratio

\footnotetext{
* Correspondence: takeyama.kiyoshi@twmu.ac.jp

'Department of Respiratory Medicine, Tokyo Women's Medical University School of Medicine, 8-1 Kawada-cho, Shinjuku-ku, Tokyo 162-8666, Japan

Full list of author information is available at the end of the article
}

(C) The Author(s). 2020 Open Access This article is licensed under a Creative Commons Attribution 4.0 International License, which permits use, sharing, adaptation, distribution and reproduction in any medium or format, as long as you give appropriate credit to the original author(s) and the source, provide a link to the Creative Commons licence, and indicate if changes were made. The images or other third party material in this article are included in the article's Creative Commons licence, unless indicated otherwise in a credit line to the material. If material is not included in the article's Creative Commons licence and your intended use is not permitted by statutory regulation or exceeds the permitted use, you will need to obtain permission directly from the copyright holder. To view a copy of this licence, visit http://creativecommons.org/licenses/by/4.0/ The Creative Commons Public Domain Dedication waiver (http://creativecommons.org/publicdomain/zero/1.0/) applies to the data made available in this article, unless otherwise stated in a credit line to the data. 


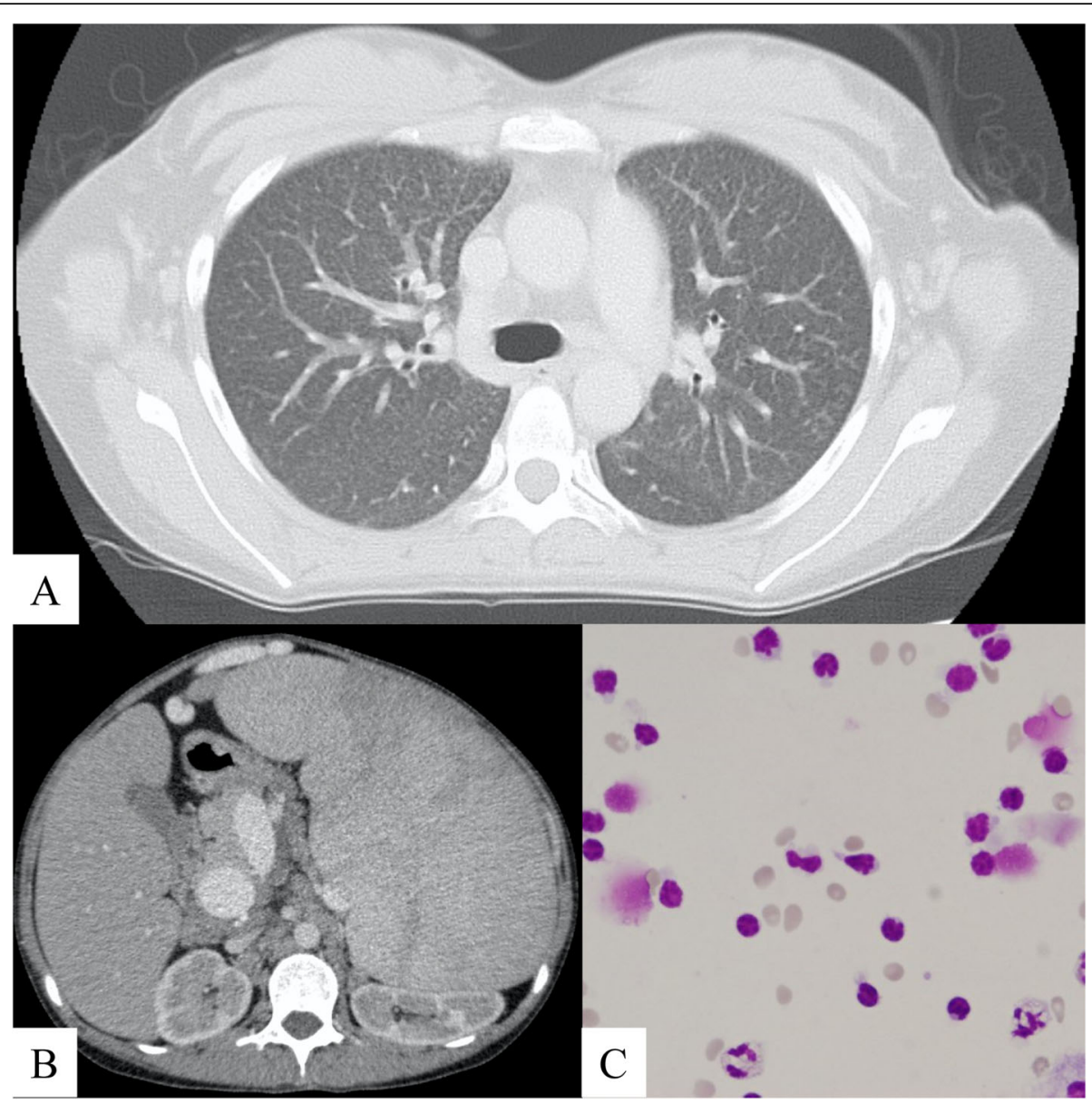

Fig. 1 a Chest computed tomography (CT) scan revealed the presence of centrilobular nodules in the lung parenchyma. b Abdominal CT scan revealed the remarkable enlargement of the spleen. c The first analysis of the bronchoalveolar lavage fluid revealed a high proportion of small lymphocytes

\section{Background}

Sarcoidosis is a systemic granulomatous disease of unknown etiology. The lungs and intrathoracic lymph nodes are the commonly affected regions, and the liver and spleen are the most commonly affected extrapulmonary organs [1, 2]. A high proportion of lymphocytes and an elevated $\mathrm{CD} 4+$ to $\mathrm{CD} 8+\mathrm{T}$-lymphocyte ratio (CD4/CD8 ratio) in the bronchoalveolar lavage (BAL) fluid (BALF) indicate CD4+ cell-dominant inflammation in sarcoidosis. Radiological findings of the lungs revealed various patterns, such as bilateral hilar lymphadenopathy, presence of perilymphatic or centrilobular small nodules, and nodular thickening along the lymphatic vessels in the bronchovascular bundle [3]. Therefore, the differential diagnosis for sarcoidosis is broad and distinguishing the condition from other respiratory diseases is sometimes challenging.

Meanwhile, diffuse panbronchiolitis (DPB) is a chronic inflammatory respiratory disease predominantly affecting East Asians [4]. The typical pathological features are observed in the respiratory bronchioles, which include peribronchial infiltration of foamy histiocytes, neutrophils, and CD8+ lymphocytes. Chest computed tomography $(\mathrm{CT})$ scan revealed centrilobular nodules and bronchial wall thickening, indicating chronic neutrophilic inflammation caused by Hemophilus influenzae or Pseudomonas aeruginosa.

Table 1 Cell count in the first bronchoalveolar lavage fluid

\begin{tabular}{lll}
\hline BALF findings & & Criterion value \\
\hline total cell (/mL) & $2.6 \times 10^{*} 5$ & $0.5 \times 10^{*} 5 \sim 2.0 \times 10^{* 5}$ \\
macrophage (\%) & 22.7 & $80 \sim 94$ \\
lymphocyte (\%) & 69.9 & $5.0 \sim 18$ \\
neutrophil (\%) & 5.8 & $0 \sim 2.0$ \\
eosinophil (\%) & 1.3 & $0 \sim 1.0$ \\
basophil (\%) & 0 & 0 \\
mast cell (\%) & 0.3 & 0 \\
CD4/CD8 ratio & 0.12 & $1.0 \sim 2.0$ \\
\hline
\end{tabular}




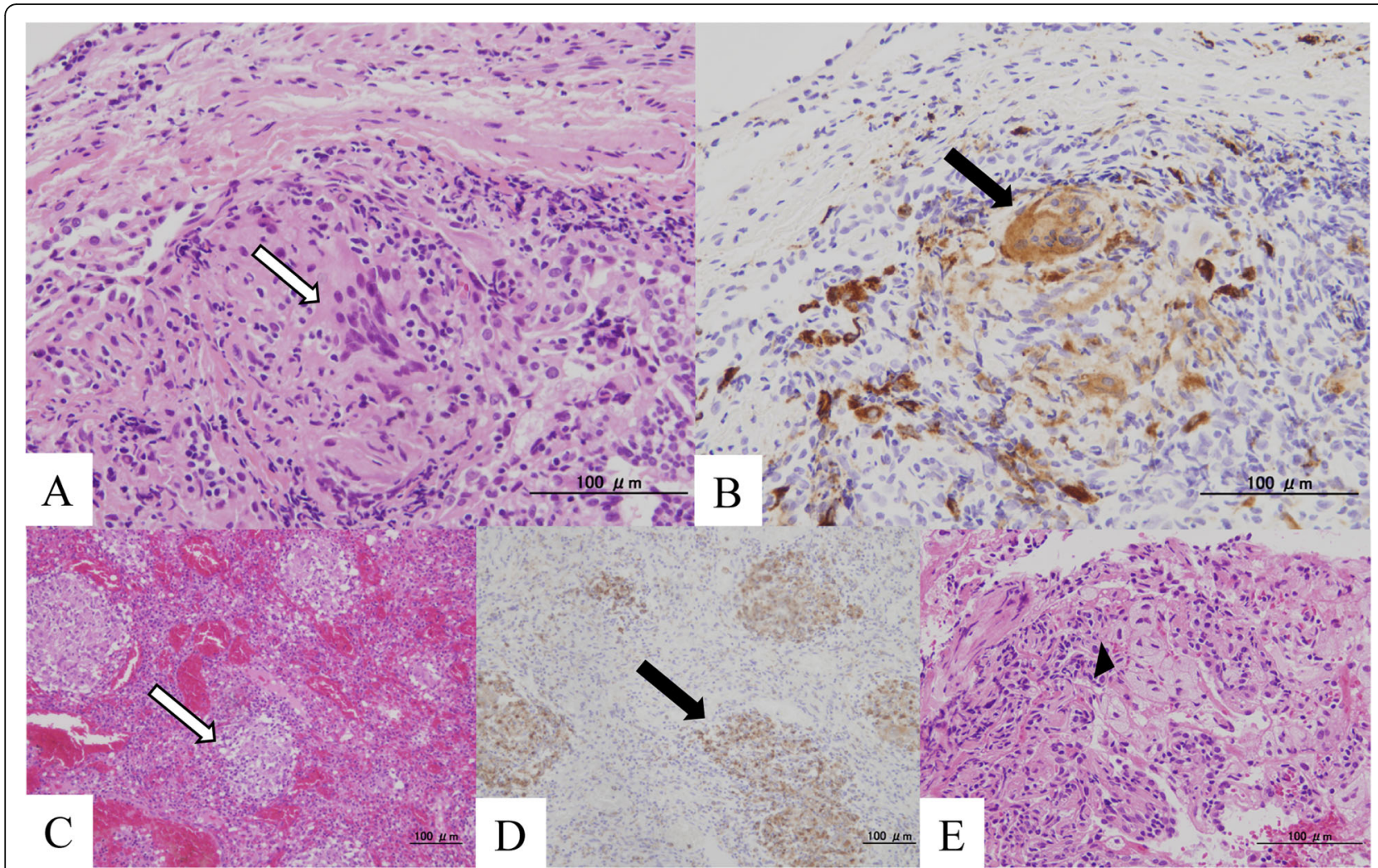

Fig. 2 a The biopsy specimen from the lung showed noncaseating granuloma with accumulation of epithelioid cells (white arrow). b Immunohistological staining of the biopsy specimen revealed the presence of CD68-positive cells, which represented epithelioid cells (black arrow). c The resected spleen had diffusely scattered noncaseating epithelioid granulomas (white arrow). d CD68-positive cells were observed in the scattered granuloma region (black arrow). e Foamy cells infiltrating the interstitial wall were observed around the respiratory bronchiole (black arrowhead)

The mechanisms of these two respiratory diseases are different, and the coexistence of sarcoidosis and DPB has not been observed in previous studies. Herein, we report a case of sarcoidosis in which the clinical presentation had become evident as DPB after splenectomy for sarcoidosis.

\section{Case presentation}

A 23-year-old Japanese woman was referred to our hospital due to splenomegaly of unknown etiology and cytopenia. Before referral, she underwent intensive examinations, including bone marrow aspiration and spleen biopsy, at other medical care centers for the detection of hematologic, endocrine, and hereditary diseases in a differential diagnosis. However, a definitive diagnosis was not made. Upon admission, the patient presented with dyspnea upon exertion and abdominal distention. Chest CT scan revealed the presence of both centrilobular and randomly distributed small nodules in both lungs (Fig. 1a). In addition, abdominal CT scan revealed splenomegaly (Fig. 1b). Lung function test upon admission revealed restrictive ventilatory impairment with reduced pulmonary diffusion capacity. Liver biopsy was performed, and the biopsy specimen revealed a noncaseating granuloma, indicating sarcoidosis. Then, the patient underwent transbronchial lung biopsy and BAL to evaluate for lung involvement. Although an increased number of small lymphocytes in the BALF, which is a typical finding, was observed, the $\mathrm{CD} 4 / \mathrm{CD} 8$ ratio decreased to 0.12 (Fig. 1c and Table 1). Moreover, the biopsy specimen from the lung showed noncaseating epithelioid granuloma positively stained with CD68 in the lung interstitium (Fig. 2a, b). The tuberculin reaction test had a negative finding. On the basis of these results and the elevated level of angiotensin-converting enzyme (ACE) $(45.1 \mathrm{U} / \mathrm{L})$, lysozyme $(36.4 \mu \mathrm{g} / \mathrm{mL})$, and serum soluble interleukin-2 receptor $(5290 \mathrm{U} / \mathrm{mL})$, the diagnosis of sarcoidosis was confirmed (Table 2). Because of progressive cytopenia and high risk of splenic rupture, splenectomy was chosen as the initial therapy. The pathological findings of the resected spleen revealed noncaseating granuloma, which was consistent with the 
Table 2 Blood test results upon admission

\begin{tabular}{|c|c|c|}
\hline Laboratory findings & & Criterion value \\
\hline WBC $(/ \mu \mathrm{L})$ & 1760 & $4000 \sim 8600$ \\
\hline $\mathrm{Neu}(\%)$ & 61.3 & $38 \sim 70$ \\
\hline Lymp (\%) & 23.9 & $27 \sim 45$ \\
\hline Mono (\%) & 11.9 & $0 \sim 7$ \\
\hline Eosino (\%) & 2.3 & $0 \sim 2$ \\
\hline $\mathrm{RBC}(/ \mu \mathrm{L})$ & $4.22 \times 10^{*} 6$ & $3.80 \times 10^{*} 6 \sim 4.80 \times 10^{*} 6$ \\
\hline $\mathrm{Hb}(\mathrm{g} / \mathrm{dL})$ & 11.1 & $12.0 \sim 16.0$ \\
\hline Hct (\%) & 35.9 & $35.0 \sim 43.0$ \\
\hline PIt $(/ \mu \mathrm{L})$ & $6.5 \times 10^{*} 4$ & $15.0 \times 10^{*} 4 \sim 35.0 \times 10^{*} 4$ \\
\hline $\mathrm{TP}(\mathrm{g} / \mathrm{dL})$ & 7.5 & $6.5 \sim 8.2$ \\
\hline Alb (g/dL) & 4.1 & $3.8 \sim 5.1$ \\
\hline T-Bil (mg/dL) & 0.9 & $0.2 \sim 1.2$ \\
\hline AST (U/L) & 45 & $13 \sim 33$ \\
\hline ALT (U/L) & 25 & $6 \sim 31$ \\
\hline $\mathrm{LDH}(\mathrm{U} / \mathrm{L})$ & 188 & $119 \sim 229$ \\
\hline ALP (U/L) & 557 & $115 \sim 359$ \\
\hline$\gamma$-GTP $(U / L)$ & 64 & $6 \sim 46$ \\
\hline $\mathrm{Cr}(\mathrm{mg} / \mathrm{dL})$ & 0.88 & $0.48 \sim 0.79$ \\
\hline BUN (mg/dL) & 8.0 & $8.0 \sim 20.0$ \\
\hline CRP (mg/dL) & 0.73 & $0 \sim 0.30$ \\
\hline ACE (U/L) & 45.1 & $7.0 \sim 25.0$ \\
\hline Lysozyme $(\mu \mathrm{g} / \mathrm{mL})$ & 36.4 & $3.4 \sim 8.6$ \\
\hline $\mathrm{KL}-6(\mathrm{U} / \mathrm{mL})$ & 1134 & $<500$ \\
\hline sIL-2R (U/mL) & 5290 & $120 \sim 500$ \\
\hline T-SPOT & negative & negative \\
\hline
\end{tabular}

splenic lesion in sarcoidosis (Figs. 2c, d). Along with the decrease in the level of serum ACE (24.1 U/L) and lysozyme $(22.4 \mu \mathrm{g} / \mathrm{mL})$, dyspnea and abdominal distention improved after splenectomy (Table 3 ).

The patient complained of gradually exacerbating dyspnea and increase in purulent sputum 3 months after splenectomy. Chest CT scan revealed the presence of centrilobular nodules with bronchial wall thickening in both lung fields (Fig. 3a). The second BAL revealed a remarkable increase in neutrophil count (Fig. 3b, Table 4). The bacterial culture from the BALF tested positive for Hemophilus influenzae. In addition, the cold agglutinin

Table 3 Blood test result after splenectomy

\begin{tabular}{lll}
\hline Laboratory findings & Criterion value \\
\hline ACE $(\mathrm{U} / \mathrm{L})$ & 24.1 & $7.0 \sim 25.0$ \\
lysozyme $(\mu \mathrm{g} / \mathrm{mL})$ & 22.4 & $3.4 \sim 8.6$ \\
SIL-2R $(\mathrm{U} / \mathrm{mL})$ & 4114 & $120 \sim 500$ \\
HTLV-1 & negative & negative \\
HIV & negative & negative \\
cold agglutinin test (titer) & 256 & $4 \sim 64$ \\
\hline
\end{tabular}

test had positive results, and paranasal sinus CT scan revealed inflammation of the maxillary sinus (Fig. 3c). Because these data showed the characteristics of DPB, we re-evaluated the lung biopsy specimen obtained during the first bronchoscopy. The foamy cells infiltrating the interstitial wall surrounding a respiratory bronchiole supported the diagnosis of DPB (Fig. 2e). Because DPB primarily caused the patient's current symptoms and radiological deterioration, $600 \mathrm{mg}$ of erythromycin was administered daily as the initial treatment. After administrating low-dose macrolide therapy for 3 months, the patient's condition improved based on the clinical and radiological findings (Fig. 4).

\section{Discussion and conclusions}

Herein, we report the coexistence of sarcoidosis and DPB, which became evident after splenectomy. The diagnosis of sarcoidosis was confirmed on the basis of the presence of noncaseating granulomas in the biopsy specimens obtained from several organs, including the liver, spleen, and lungs. Increased lymphocyte count in the BALF is commonly observed in patients with sarcoidosis; the CD4+ lymphocytes infiltrate into the alveoli, causing the high $C D 4 / C D 8$ ratio in the BALF [1, 2]. However, the $C D 4 / C D 8$ ratio in the BALF in the present case was low (0.12), which was not consistent with sarcoidosis. A CD4/CD8 ratio $<1$ is observed in $12 \%$ of patients with sarcoidosis confirmed via biopsy [5]. However, the cause of CD8+ lymphocyte predominance in sarcoidosis is not completely understood. In the present case, DPB might have affected the CD4/CD8 ratio in the BALF. Because neutrophils and CD8+ lymphocytes play a role in the development of $\mathrm{DPB}$, the migration of $\mathrm{CD} 8+$ lymphocytes into the alveoli might have resulted in a low CD4/CD8 ratio in the BALF [6].

Splenectomy might have triggered the exacerbation of DPB. The levels of serum ACE and lysozyme, which reflect the disease activity of sarcoidosis, decreased after splenectomy. By contrast, the presence of centrilobular nodules, which is one of the radiological features of $\mathrm{DPB}$, was found on chest CT scan in the current case. Furthermore, the second BAL revealed both increased proportion of neutrophils and a positive bacterial culture for Hemophilus influenzae. Since splenectomy is a risk factor for infectious diseases caused by Hemophilus influenza, it may explain the exacerbation in DPB.

In the present case, the histological features of DPB were also confirmed; biopsy specimens obtained during the first bronchoscopy showed accumulation of foamy cells around the respiratory bronchioles where the distinctive feature is observed in patients with DPB [7]. The deterioration of bronchiolitis was successfully treated with a low-dose macrolide therapy. Similarly, a sarcoidosis case that diagnosed during the clinical course of 


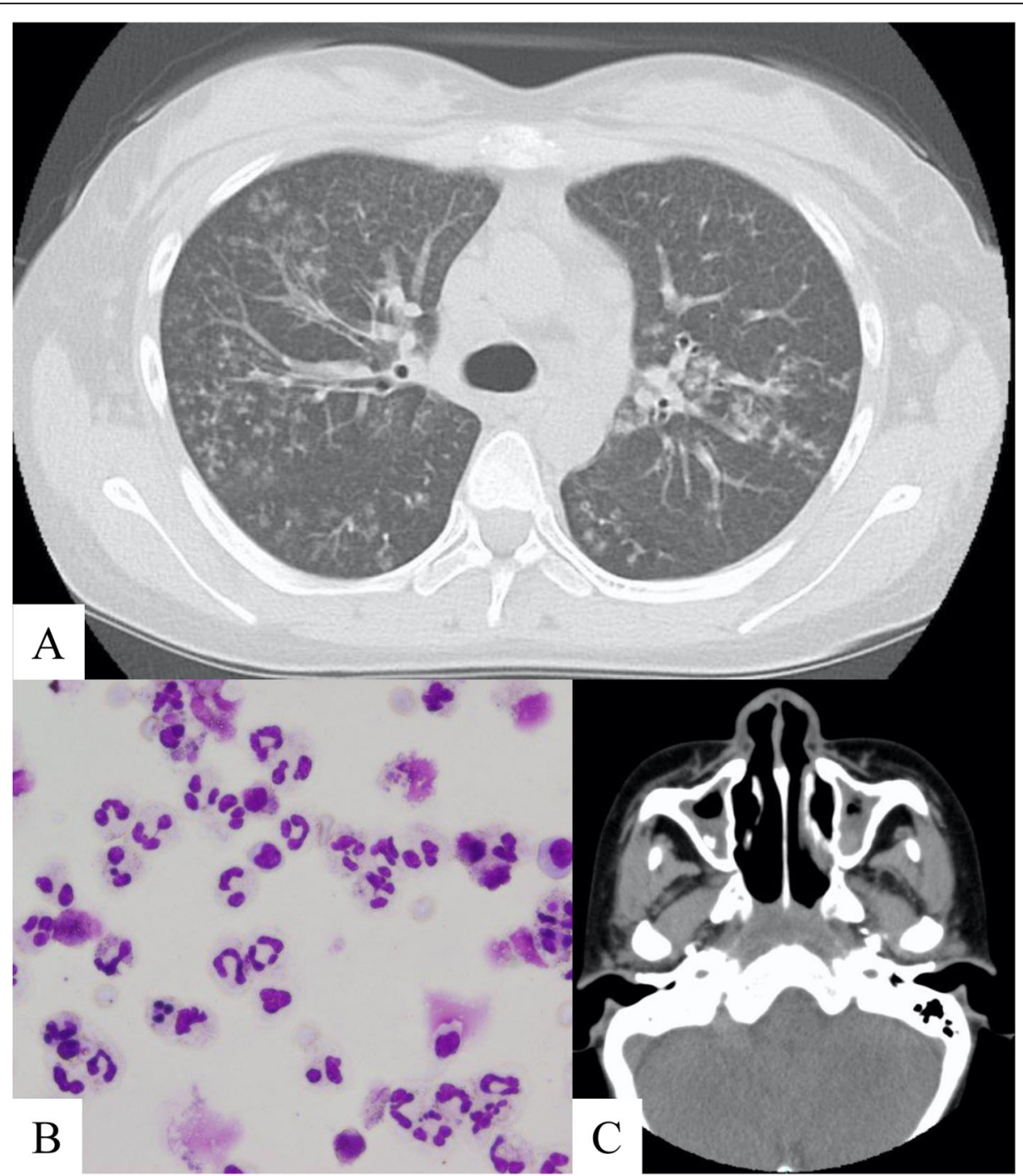

Fig. 3 a Chest computed tomography (CT) scan revealed bronchial wall thickening and presence of centrilobular nodules 3 months after splenectomy. b The second analysis of the bronchoalveolar lavage fluid revealed a remarkable increase in neutrophil count. c Paranasal sinus CT scan revealed thickening of the maxillary sinus wall

Table 4 Cell count in the second bronchoalveolar lavage fluid

\begin{tabular}{lll}
\hline BALF findings & & Criterion value \\
\hline total cell (/mL) & $2.3 \times 10^{*} 5$ & $0.5 \times 10^{*} 5 \sim 2.0 \times 10^{* 5}$ \\
macrophage (\%) & 0.7 & $80 \sim 94$ \\
lymphocyte (\%) & 5.3 & $5.0 \sim 18$ \\
neutrophil (\%) & 94 & $0 \sim 2.0$ \\
eosinophil (\%) & 0 & $0 \sim 1.0$ \\
basophil (\%) & 0 & 0 \\
mast cell (\%) & 0 & 0 \\
CD4/CD8 ratio & 0.09 & $1.0 \sim 2.0$ \\
\hline
\end{tabular}

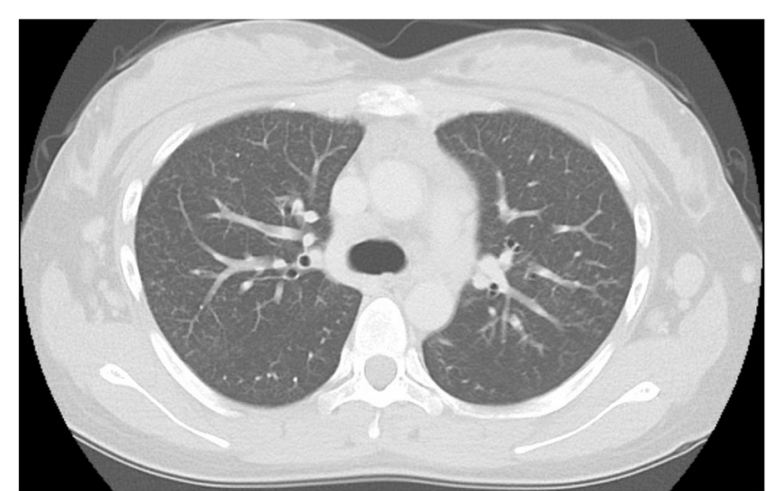

Fig. 4 The pattern of centrilobular nodules slightly improved after the initiation of macrolide therapy 
idiopathic bronchiolitis mimicking DPB was improved by erythromycin [8].

In conclusion, the present case highlighted the complex presentation of the coexistence of sarcoidosis and DPB. If a patient with sarcoidosis presents with an atypical disease presentation, the coexistence of other diseases should be considered.

\section{Abbreviations}

CD4/CD8 ratio: CD4+ to CD8+ T-lymphocytes; BALF: Bronchoalveolar lavage fluid; DPB: Diffuse panbronchiolitis; CT: Computed tomography;

ACE: Angiotensin-converting enzyme

\section{Acknowledgements}

We would like to thank the patient for allowing us to share the case with the scientific community.

\section{Authors' contributions}

TA, TK, and MK drafted the manuscript. TA, FK, AO, ST, and ET contributed to the diagnosis and treatment of the patient. TK, MK, and ET reviewed and edited the manuscript. All authors approved the final version of the manuscript.

\section{Funding}

The authors received no financial support for the research, authorship, or publication of this article.

\section{Availability of data and materials}

All data and materials of this article are included in the manuscript and are available to the readers.

\section{Ethics approval and consent to participate}

Not applicable.

\section{Consent for publication}

A written informed consent was obtained from the patient for the publication of this case report

\section{Competing interests}

The authors declare that they have no competing interests.

\section{Author details}

'Department of Respiratory Medicine, Tokyo Women's Medical University School of Medicine, 8-1 Kawada-cho, Shinjuku-ku, Tokyo 162-8666, Japan. ${ }^{2}$ Division of Pathological Neuroscience, Department of Pathology, Tokyo Women's Medical University School of Medicine, Tokyo, Japan.

Received: 5 January 2020 Accepted: 16 March 2020

Published online: 30 March 2020

\section{References}

1. The ATS Board of Directors and the ERS Executive Committee. Statement on Sarcoidosis. Joint Statement of the American Thoracic Society (ATS), the European Respiratory Society (ERS) and the World Association of Sarcoidosis and Other Granulomatous Disorders (WASOG). Am J Resipir Crit Care Med. 1999;160:736-55

2. Soto-Gomez N, Peters Jl, Nambiar AM. Diagnosis and management of sarcoidosis. Am Fam Physician. 2016;93:840-8.

3. Park HJ, Jung Jl, Chung MH, Song SW, Kim HL, Baik JH, et al. Typical and atypical manifestations of intrathoracic sarcoidosis. Korean J Radiol. 2009;10: 623-31.

4. Homma H, Yamanaka A, Tanimoto S, Tamura M, Chijimatsu Y, Kira S, et al. Diffuse panbronchiolitis. A disease of the transitional zone of the lung Chest. 1983:83:63-9.

5. Kantrow SP, Meyer KC, Kidd P, Raghu G. The CD4/CD8 ratio in BAL fluid is highly variable in sarcoidosis. Eur Respir J. 1997:10:2716-21.

6. Mukae H, Kadota J, Kohno S, Kusano S, Morikawa T, Matsukura S, et al. Increase in activated CD8+ cells in bronchoalveolar lavage fluid in patients with diffuse panbronchiolitis. Am J Respir Crit Care Med. 1995;152:613-8.
7. Poletti V, Casoni G, Chilosi M, Zompatori M. Diffuse panbronchiolitis. Eur Respir J. 2006:28:862-71.

8. Trisolini R, Cancellieri A, Paioli D, Burzi M, Orlandi P, Patelli M. Sarcoidosis in the setting of idiopathic chronic bronchiolitis with airway colonization from P. aeruginosa: treatment with low-dose macrolides. Intern Med. 2008;47(6): 537-42.

\section{Publisher's Note}

Springer Nature remains neutral with regard to jurisdictional claims in published maps and institutional affiliations.
Ready to submit your research? Choose BMC and benefit from:

- fast, convenient online submission

- thorough peer review by experienced researchers in your field

- rapid publication on acceptance

- support for research data, including large and complex data types

- gold Open Access which fosters wider collaboration and increased citations

- maximum visibility for your research: over $100 \mathrm{M}$ website views per year

At BMC, research is always in progress.

Learn more biomedcentral.com/submission 